\title{
DISCURSOS SOBRE EDUCAÇÃO FÍSICA ESCOLAR E O PROTAGONISMO DA MIDIATIZAÇÃO ESPORTIVA
}

\author{
Fábio Soares da Costa \\ Pontifícia Universidade Católica do Rio Grande do Sul, Porto alegre, Rio Grande do sul, Brasil. \\ Janete de Páscoa Rodrigues \\ Universidade Federal do Piauí, Teresina, Piauí, Brasil. \\ Andreia Mendes dos Santos \\ Pontifícia Universidade Católica do Rio Grande do Sul, Porto alegre, Rio Grande do sul, Brasil.
}

\begin{abstract}
Resumo
A pesquisa desenvolve reflexões sobre sentidos enunciados em reportagens exibidas no programa televisivo Esporte espetacular durante o mês de janeiro de 2017. O conjunto enunciativo investigado apresentou como as aulas de Educação Física escolar são desenvolvidas em quatro países: Brasil, Inglaterra, Estados Unidos e Japão. Metodologicamente, a Análise de Discurso Crítica (ADC) proporcionou a identificação das representações relacionais entre esporte e educação e as estratégias discursivas construídas nessas reportagens. A reflexão sobre o texto/imagem como discurso social e a potência das representações esportivas como fenômeno discursivo e ideológico torna a enunciação esportiva o currículo majoritário no ambiente educacional relativo às aulas de Educação Física escolar.
\end{abstract}

Palavras-chave: ADC. Educação física. Escola. Esporte.

\section{DISCOURSES ON SCHOOL PHYSICAL EDUCATION AND THE PROTAGONISM OF SPORTS MEDIATIZATION}

\begin{abstract}
The research develops reflections on the meanings expressed in reports presented in the television program Esporte Espetacular during the month of January, 2017. The enunciative set investigated presented how the school physical education classes are developed in four countries: Brazil, England, United States and Japan. Methodologically, the Critical Discourse Analysis (ADC) provided the identification of the relational representations between sport and education, and the discursive strategies constructed in these reports. The reflection on the text/image as a social discourse and the power of sports representations as a discursive and ideological phenomenon, makes sports enunciation the main curriculum in the educational environment related to school physical education classes.
\end{abstract}

Keywords: ADC. Physical education. School. Sport. 


\title{
DISCURSOS SOBRE EDUCACIÓN FÍSICA ESCOLAR Y EL PROTAGONISMO DE LA MEDIATIZACIÓN DEPORTIVA
}

\begin{abstract}
Resumen
La investigación desarrolla reflexiones sobre los significados enunciados en los informes mostrados en el programa de televisión Esporte espectacular durante el mes de enero de 2017. El conjunto enunciativo investigado presentó cómo se desarrollan las clases de Educación Física en cuatro países: Brasil, Inglaterra, Estados Unidos y Japón. Metodológicamente, el Análisis Crítico del Discurso (ADC) proporcionó la identificación de las representaciones relacionales entre el deporte y la educación y las estrategias discursivas construidas en estos informes. La reflexión sobre el texto / imagen como un discurso social y el poder de las representaciones deportivas como un fenómeno discursivo e ideológico hacen de la enunciación deportiva el currículo principal en el entorno educativo relacionado con las clases de educación física escolar.
\end{abstract}

Palabras clave: ADC. Educación Física. Escuela Deporte.

\section{Introdução}

A Educação Física, como disciplina de ensino escolar, consolidada por sua notória importância como mediação de aprendizagem na escola vem sendo demasiado discutida nestes tempos, sobremaneira pelas mudanças sobre seu desenvolvimento no ensino médio. Fortalecida pelas pesquisas científicas das humanidades e da saúde que analisam os aspectos inerentes ao desenvolvimento físico, afetivo, cognitivo, motor e emocional humano, vem sofrendo um processo de secundarização, principalmente quando considerada estratégia pedagógica. É pensada em um ambiente político legislativo e executivo que ignora sua essencialidade na constituição de um sujeito plural, cultural e crítico, que tem nas diversas vivências corporais a oportunidade de pensar sobre si e o ambiente que constitui e é constituído.

A Educação Física escolar é, também, considerada pauta, notícia, fundamento esportivo midiático, discurso educacional e itinerário de uma cultura esportiva midiatizada que persuade cada vez mais seus receptores por vias da televisão, ainda mais se relacionada intimamente à figura de heróis esportivos que tiveram sua trajetória de sucesso iniciada nessas aulas.

A relação estabelecida entre a mídia e a Educação Física escolar, e sobremaneira a mídia televisiva, tem nos instigado a pensar como o telespectador vem sendo informado sobre o papel da Educação Física escolar na vida dos educandos, como se constitui, como é desenvolvida, seus benefícios, dificuldades e estratégias para o desenvolvimento de valores educacionais em tempos de liquidificação ${ }^{1}$ política, administrativa e educacional vividos hoje.

Nesta perspectiva, enunciamos como problemática deste estudo perceber quais as representações de currículo são propostas pela TV aberta a partir de programas, ditos especializados. Como as enunciações identificadas em reportagens que anunciam a Educação Física escolar, como núcleo de discussão pedagógica, acionam sentidos sobre desenvolvimento pedagógico e seus objetivos educacionais? Que elementos culturais, informativos e educacionais são produzidos, recebidos e postos em circulação a partir do suporte midiático televisivo, que é um dos principais meios de veiculação dos sentidos de relação entre esporte, educação e Educação Física?

\footnotetext{
${ }^{1}$ Usamos este termo para apresentar o atual estado de mistura e confusão no processo de mudanças na legislação educacional, que projeta um lugar pedagógico minoritário para a Educação Física na escola. A ideia inicial de uma facultatividade do seu exercício no ensino médio, que culminou em uma orientação para estudos e práticas secundarizados e o desaparelhamento escolar para o seu desenvolvimento em perspectiva líquida instantânea.
} 
As respostas a essa problemática iniciam-se com a apresentação reflexiva teórica sobre enunciação e discurso do gênero da televisão, como discurso social e sobre as representações de educação, como fenômeno discursivo e ideológico. Os modos de enunciação da relação estabelecida entre o esporte e as aulas de Educação Física escolar são suportes desta análise, que se fundamenta na Teoria dos Discursos Sociais, bem como na perspectiva em que fenômenos educacionais são transversalizados por fenômenos comunicacionais.

O corpus de análise é constituído por uma série de reportagens exibidas pela Rede Globo de Televisão por meio do programa Esporte espetacular, de 8 a 29 de janeiro de 2017. Esse programa é exibido semanalmente aos domingos e apresenta quadros relacionados às manifestações esportivas educacionais, de lazer e de rendimento e entretenimento. Essa escolha foi motivada pelo núcleo discursivo das reportagens, aliado à sua exibição em um programa que apresenta uma média histórica de 10 pontos de audiência aos domingos, ou seja, aproximadamente, $6.842 .020^{2}$ telespectadores assistiram aos episódios que constituem esse corpus.

\section{Percursos metodológicos}

\section{Enunciação e discurso}

Michel Foucault (1995), em Arqueologia do saber, esboçou em seu tempo certa impossibilidade de apresentar conceituações satisfatórias a respeito de enunciação e de discurso, haja vista a complexidade para um entendimento aprofundado e condizente com as defesas teórico-metodológicas existentes na época. Não obstante, neste estudo, recorremos a Magalhães (2003), Fairclough (2001), Bakhtin (2004) e Verón (2004), no intento de apresentar de maneira mais didática esses conceitos.

Para Verón (2004), a relação conceitual entre enunciação e enunciado é indissolúvel, pois se imbrica na assertiva de que enunciação é da ordem do dizer e enunciado é da ordem do dito. Assim, como matéria enunciativa do discurso, é o enunciado e, como os modos de dizer, é a enunciação.

Fairclough (2001), ao tratar de enunciação, valoriza a fala, creditando-a acessibilidade e validade para estudos sistemáticos de correlação com variáveis sociais. Todavia, faz uma distinção: o ato de falar é individual, contudo, a fala é social, é compartilhada socialmente. Perspectiva análoga à de Bakhtin (2004), que relaciona a enunciação com o ato da fala, inserindo o aspecto social no processo, pois " $\mathrm{Na}$ realidade, o ato de fala, ou, mais exatamente, seu produto, a enunciação, não pode de forma alguma ser considerado como individual no sentido estrito do termo; não pode ser explicado a partir das condições psicofisiológicas do sujeito falante" (BAKHTIN, 2004, p. 111).

Para Fairclough (2001), que desenvolve sua defesa conceitual a partir de Michel Foucault, o discurso deve pensar o uso da linguagem como prática social, um modo de ação e representação, dialeticamente imbricado com a estrutura social. Relaciona-se com a linguagem a partir de três de suas funções: a identitária, a relacional e a ideacional.

Nesse contexto, é evidente seu posicionamento de que a linguagem é um meio de representação do mundo, de interação e organização de informações e assim se desenvolve através dos modos como as identidades sociais se encontram estabelecidas nos discursos (função identitária), a partir das relações sociais exercidas entre os participantes do discurso, seus processos de representação e negociação (função relacional), assim como pelo

\footnotetext{
2 Projeção apresentada pela coluna IBOPE MEDIA. Disponível em: $<$ http://natelinha.uol.com.br/noticias/2016/01/07/ibope-atualiza-representatividade-de-1-ponto-de-audienciaveja-comparativo-95454.php>. Acesso em: 9 mar. 2017.
} 
entrecruzamento do mundo, dos processos, das entidades e das relações, em um processo denominado pelo autor como função ideacional.

Por isso, Fairclough (2001) afirma que a prática discursiva é tributária da reprodução social, das identidades sociais, das relações sociais, dos sistemas de conhecimento e das crenças. Contudo, também é tributária da transformação social, materializada na forma linguística, através de textos e imagens, como nos programas televisivos aqui em questão.

\section{Mídia televisiva e a análise de discurso crítica}

A escolha em analisar reportagens televisivas se deu ao percebermos que, nos discursos de comunicação de massa (televisivos), as narrativas se relacionam com o acontecido e com a forma de contá-lo. Assim, pensamos que o conjunto de reportagens em análise foi construído pelas discussões em curso sobre a obrigatoriedade das aulas de Educação Física no ensino médio, propostas pelo Poder Executivo nacional, à época com a Medida Provisória 746/2016, posteriormente revogada pela edição da Lei 13.415/2017, que, alicerçada em itinerários formativos, se apresenta em formato utilitarista no que diz respeito ao conhecimento e dualista quanto ao ensino (propedêutico e profissional), refletindo um distanciamento em relação à formação integral do educando, com clara desvalorização da Educação Física escolar.

Observar como se constrói o presente jornalístico revelador do fato, a construção dos seus discursos e como estes operam é o nosso propósito investigativo, pois a oferta de um presente social contínuo promovido pela televisão é fundamento de reflexão teórica e metodológica que nos auxilia na compreensão sobre uma pedagogia de sentidos ofertada pela televisão. Esse engendramento e é esclarecido por Fischer e Chiappini, a seguir.

Fischer defende que:

A leitura audiovisual mais qualificada expande a capacidade de compreender, distinguindo e ao mesmo tempo integrando conteúdos e formas. Apura a percepção visual e auditiva, permitindo identificar e apreciar a composição imagem/som/texto, que é a própria essência dessa linguagem e fonte de sua atração. (FISCHER, 2006, p. 117).

Assim, entendemos que essa leitura vem sendo utilizada com fins educacionais, mesmo que pela TV, pois essa pedagogia televisa torna-se cada vez mais vigente.

Este é um pensamento que se conecta com o de Chiappini (2004), sobre o papel estratégico da TV no terreno da cultura, quando se constitui como parte integrante e premente de atenção, pois a construção histórica de nossos valores e educação é cultural e mediada pela TV, inclusive. Daí, optarmos pela Análise de Discurso Crítica (ADC) como estudo, método e análise dessas questões.

Dessa forma, descrever, interpretar e explicar ${ }^{3}$ relações entre a mídia e o fundamento educacional em plataformas midiáticas é importante, pois assim é possível problematizar sua influência e a relação com os sentidos destinados ao telespectador/aprendente. Nesse contexto de análise, estudos que envolvam linguagem e significação (como os de mídia televisiva) necessitam de fundamentos teórico-metodológicos para o seu desenvolvimento. Por isso escolhemos a ADC, acreditando que esta consegue, satisfatoriamente, desenvolvê-los e alcança dimensões relacionadas à ideologia e às relações de poder.

A prática discursiva é fundamentada na intertextualidade e, como condição de prática social, trata a linguagem como parte da sociedade, pois é um processo social, não estando a

\footnotetext{
${ }^{3}$ São as principais etapas do método da Análise de Discurso Crítica (FAIRCLOUGH, 2001).
} 
sociedade à sua margem, mas no seu interior. Assim, a linguagem é condicionada socialmente, e nem sempre por vetores linguísticos (FAIRCLOUGH, 2001, p. 29-30).

Nosso corpus de análise é formado por textos, ${ }^{4}$ aqui considerados como eventos sociais, inseridos em práticas sociais de linguagem que, por sua vez, pertencem a estruturas abstratas sociais, econômicas, políticas e culturais. Dizem respeito à própria linguagem, como sistema de possibilidades. Portanto, as estruturas e as práticas sociais pertencem ao contexto de cultura, enquanto os eventos, refletidos nos textos, pertencem a um contexto situacional.

Nesse sentido, esta pesquisa envolve uma análise das enunciações sobre as aulas de Educação Física escolar a partir do suporte midiático televisivo - reportagens exibidas no programa Esporte espetacular. Para tanto, em razão de a ADC não possibilitar a realização de análises textuais isoladas, as análises desenvolvidas neste estudo vislumbram o contexto de situação, as práticas sociais que envolvem o exercício das aulas de Educação Física na escola articulados a um contexto cultural maior - a relação entre o esporte e essas aulas. Embora a análise parta de um corpus textual específico, ela sempre se remeterá às práticas sociais, sendo que o discurso, em suas representações linguísticas e semióticas, é apenas um momento dessa complexa rede no contexto cultural.

Assim, o desencadeamento analítico realizado é orientado pelo modelo tridimensional de Fairclough (2001), que reúne três pilares analíticos: a análise textual, a prática discursiva e a prática social, metodologicamente organizado em três momentos: 1) a descrição (apresentação das propriedades formais do texto, pois são plenas de sentido); 2) a interpretação (momento de relacionar textos com outros textos, em que se percebe a formação do outro), e 3) a explicação (a reflexão e a exposição da análise realizada).

\section{Resultados e discussão: descrição, interpretação e explicação do "esporte na escola"5}

\section{Brasil: a Educação Física no ensino médio é importante, mas facultativa?}

O primeiro episódio foi exibido em 8 de janeiro de 2017, teve duração de 12 minutos e 34 segundos e apresenta um panorama da Educação Física escolar no Brasil. O início da série é marcado pela promessa do apresentador de que a realidade da Educação Física no Brasil e no mundo será desvelada. A reportagem se inicia com a enunciação de princípios importantes da Educação Física escolar como respeito, determinação e solidariedade, além do indicativo de revelar respostas para a pergunta: o que é Educação Física?

Todas as reportagens utilizam entrevistas testemunhais e temáticas. Nesse episódio, foram realizadas com professores, diretores, secretário, atletas e alunos para desenvolver uma perspectiva de credibilidade informativa e confirmação das narrativas do repórter. As vozes são múltiplas, no entanto, marcamos notadamente as dos apresentadores, do repórter, de um professor de Educação Física de ensino superior, do secretário de Educação Básica do Ministério da Educação, de alunos e de uma ex-aluna, agora atleta de voleibol, de professoras de Educação Física e uma diretora de escola da educação básica.

À época da exibição dessa série de reportagens, uma medida provisória que objetivava alterações no texto da LDB 9694/96 havia sido editada pelo governo federal. A Medida Provisória $\mathrm{n}^{\circ} 746$, de 22 de setembro de 2016 (BRASIL, 2016), em seu texto, restringia a obrigatoriedade do ensino da Educação Física à educação infantil e ao ensino fundamental, tornando-a facultativa no ensino médio. Essa medida foi fator desencadeador e motivador para essas discussões, principalmente porque a condição de importância das atividades físicas para a educação escolar em contraposição à proposta de sua facultatividade precisava ser

\footnotetext{
${ }^{4}$ Apresentamos o termo texto como sinonímia de apresentação audiovisual inerente às reportagens televisivas.

${ }^{5}$ A expressão está assim grafada - esporte na escola - por conta de se tratar do título dado à série de reportagens exibidas no programa Esporte espetacular.
} 
discutida. As discussões sobre essas mudanças e a convicção da sua necessidade no currículo escolar motivaram o exercício de uma reflexão enunciada na reportagem: "Qual o tamanho da importância da Educação Física na vida de uma pessoa?" Assim como sobre o que é Educação Física. Uma resposta veiculada foi: "[...] é aquele conjunto de atividades que faz um bem danado à cabeça e ao corpo" (0 min. 15 seg.).

Acreditamos que esse conceito de Educação Física ofertado na reportagem é simplificado. Que precisa de melhor exploração em busca de uma complexificação necessária aos objetivos que a disciplina tem. Essa visão dualista já foi superada por diversos estudos do campo acadêmico, contudo, ainda se vê reforçada hoje e viva no imaginário e na subjetividade das pessoas. Pensamos diversamente e entendemos que a perspectiva nuclear da profissão está centrada na educação corporal, em uma discussão que envolva valores coletivos, a percepção do eu e o cuidado de si para ser possível o cuidado do outro, que revele nossos limites e possibilidades em manifestações muito mais diversas do que as esportivas apenas.

O componente ideológico da mídia é materializado em parte importante da reportagem. Apesar da afirmação do apresentador do programa de que "O repórter Kiko Meneses foi a vários lugares do Brasil pra mostrar como é a situação por aqui” (23 seg.), em verdade, apenas duas realidades foram abordadas: 1) a escola pública municipal GEO, no Rio de Janeiro: a escola-modelo, e 2) a escola pública municipal Nossa Senhora Aparecida, em Jaboatão dos Guararapes, Pernambuco: a escola precária.

A escola apresentada como modelo é o GEO - Ginásio Experimental Olímpico. Em sua referência, a narrativa jornalística relaciona como ponto positivo o de que essa escola tem como objetivo principal trabalhar para que todos os alunos possam ser bons atletas. Essa perspectiva privilegia a esportivização competitiva e negligência enunciações importantes para uma reportagem que trata dos princípios que a disciplina Educação Física tem. Aspectos educacionais e valores importantes para a constituição de um sujeito cooperativo, sensível corporalmente e cidadão comprometido com o mundo ao seu redor são secundarizados em prol de uma única possibilidade: a de ser atleta. Essa perspectiva é consolidada pela afirmação da diretora do GEO: "Vamos dizer que é uma grande casa de formação de atletas" (7 min. 10 seg.).

O GEO recebe destaque, sobremaneira, por sua estrutura física (ginásios, quadras, campo de futebol, piscina, pista de atletismo, aparelhos de musculação), ou seja, lá "[...] Você tem tudo que você precisa pra ser um ótimo atleta" (6 min. 40 seg.). E a relação de sucesso educacional apresentada é a de que o aluno bom é o que será um atleta de sucesso.

Entre as duas realidades, percebemos que o protagonismo enunciativo dos alunos ficou evidente nas narrativas dos estudantes da escola pública nordestina. A contraposição entre os entraves relacionados pela falta de estrutura esportiva e os sentimentos enunciados pelas crianças descortina um equívoco aparente na narrativa jornalística: a relação confusa entre os objetivos das aulas e a estrutura física para o seu desenvolvimento.

Sobre esse aspecto, relativizamos nossa posição ao concordarmos sobre a importância de se ter um local adequado para o desenvolvimento das aulas de Educação Física. No entanto, divergimos de que esse espaço deve ser adequado objetivamente à prática esportiva. Na Educação Física, outras tantas manifestações corporais devem ser mais exploradas, difundidas e evidenciadas como suporte pedagógico para o desenvolvimento de um sujeito integral, holístico e vivente em um mundo que precisa ser menos competitivo. E se a esportivização que vem sendo desenvolvida ancora-se nesse princípio, entendemos estar equivocada.

Em meio a esses pontos nevrálgicos que precisam ser repensados quando tratamos de uma Educação Física plural, que privilegie a diversidade de formas, movimentos e sensações, identificamos alguns pontos interessantes na reportagem que precisariam de maior destaque, 
como a assertiva da professora de que as vivências motoras e suas variedades vivenciadas nas aulas de Educação Física serviram de alicerce para o desenvolvimento de atividades especializadas na idade adulta. Também quando o GEO foi tratado como um lugar onde o badminton tem a mesma importância da matemática, apresentando a equivalência de valor educacional entre as atividades físicas e as consideradas cognitivas apenas.

Ao mesmo tempo em que a diretora do GEO acredita que aquele lugar é um celeiro de potenciais talentos esportivos, também considera que "A Educação Física leva as crianças a ter um conhecimento mais amplo, maior de si, do amigo, do companheiro" (11 min. $30 \mathrm{seg}$.). Esse aspecto reforça uma questão importante em meio às narrativas: a de que a Educação Física desenvolve valores como companheirismo, amizade, cooperação, socialização, respeito às regras e igualdade. Assim, sendo mais holística e plural, sem se servir apenas do esporte como suporte redentor e educacional.

\section{Inglaterra: Millfield é a excelência em educação física}

O segundo episódio da série foi exibido no dia 15 de janeiro de 2017, com duração de 11 min. e $51 \mathrm{seg}$. e tratou da forma como a Inglaterra considera importante a Educação Física, sobretudo como preparação para o esporte e o desenvolvimento de atletas olímpicos e paralímpicos com excelente estrutura e professores ex-atletas.

A narrativa jornalística é iniciada com a apresentação da escola Millfield, notabilizada por sua estrutura arquitetônica e esportiva. $\mathrm{O}$ ensejo de iniciar a comparação com o episódio anterior não é perdido, como percebemos aos $30 \mathrm{seg}$. de matéria, quando o repórter narrador diz:

É difícil encontrar estrutura igual. Os campos, quadras, pistas e piscinas estão sempre em perfeito estado. Prontos pra receber praticantes de 28 modalidades. Equipamentos de última geração e a orientação vêm de treinadores renomados. Muitos deles, medalhistas olímpicos. Muito atleta profissional no Brasil deve sonhar com um lugar assim. Mas nem adiante, porque não se trata de um clube, nem de um centro de treinamento de uma grande potência esportiva. Isso é uma escola! (Grifo nosso).

O objetivo da escola é formar bons alunos. Mas o que se entende por isso? São alunos que resolveram investir na carreira acadêmica, mas, para isso, têm que praticar esportes e se movimentar. Assim, já vislumbramos uma perspectiva comparada de contraposição aos objetivos que, à época, a Medida Provisória $n^{\circ}$ 746/2016 defendia, a facultatividade da Educação Física no ensino médio brasileiro, mas que não foi materializada pela Lei $\mathrm{n}^{\circ}$ 13.415/2017, apenas secundarizada em meio ao formato dos itinerários formativos.

O reitor da escola inglesa pensa que "Não há dúvidas de que a Educação Física é uma parte importante do desenvolvimento. Nosso cérebro não vive divorciado de nosso corpo e os jovens precisam de atividades físicas pra que consigam atingir o melhor das habilidades dentro da classe" (1 min. $45 \mathrm{seg}$.). O planejamento e a execução das atividades nessa escola são fundamentados por resultados de pesquisas científicas que afirmam haver importante estímulo do córtex pré-frontal (responsável pelo planejamento, pela execução, pelo foco e pela memória de nossos pensamentos) quando se pratica alguma atividade física. Ou seja, "[...] quem se movimenta está mais apto para aprender" (2 min.19 seg.). Para professores e diretor de esportes da mesma escola, o rendimento em sala de aula deve ser equilibrado com o rendimento nas aulas de Educação Física.

Em seguida, o narrador do programa da Rede Globo comenta: "Esse pensamento do reitor pode soar estranho quando se vê a Educação Física como algo sem relação com o que ocorre dentro da sala de aula" ( 2 min. 4 seg.). Tal enunciação revela certa legitimação de um 
discurso em que a Educação Física e os conhecimentos científicos vistos em sala de aula ocupam espaços distintos no universo dos saberes.

A matéria destaca ainda que a exigência mínima em Millfield é de seis horas por semana dedicadas às atividades físicas e esportivas. Já no Brasil, a exigência prevista na Lei 13.415/2017 é de duas horas por semana.

Apesar da conjuntura observada nas entrevistas - relação importante entre a educação e o movimento -, a narrativa jornalística do programa Esporte espetacular retoma sua defesa enunciativa principal: o rendimento esportivo como fim das aulas de Educação Física:

Em termos acadêmicos, a instituição está entre as melhores do Reino Unido e ao mesmo tempo virou um celeiro de talentos esportivos. (3 min. $7 \mathrm{seg}$.).

Os nomes dos alunos esportistas ficam expostos. São motivo de orgulho. Afinal, eles têm mais conquistas que muito país por aí. Millfield formou até hoje 68 atletas olímpicos e paralímpicos, que conquistaram 12 medalhas. [...] Esse é o caso de James Guy. Um prodígio da natação britânica. Hoje ele tem 21 anos e duas pratas olímpicas no currículo, conquistadas aqui no Brasil, nos jogos do Rio. (3 min. 51 seg.).

Poderia e foi muito melhor. O melhor. Em 2012, levou dois ouros olímpicos nos jogos de Londres - nos 5.000 e nos 10.000 metros. Foi bicampeão nas duas provas no ano passado no Rio. (10 min. $39 \mathrm{seg}$.). (Grifos nossos).

Estrutura física exemplar e incentivo ao esporte são as principais nuanças de destaque ao se falar das aulas de Educação Física em Millfield. No entanto, em perspectiva comparativa com a realidade brasileira, esta não nos parece uma opção imparcial, pois as instituições brasileiras apresentadas são públicas e reféns de uma gestão política desacreditada nestes tempos. Todavia, um exemplo de iniciativa pessoal e partindo de um professor leigo é apresentada como alternativa para o exercício da prática esportiva nas aulas de Educação Física e sem investimentos significativos. Para isso, a narrativa jornalística arrebata: "Só um professor entusiasmado e uma garotada com vontade de se movimentar" (5 min. $35 \mathrm{seg}$.).

As duas abordagens são um tanto românticas e a serviço de uma perspectiva que pensa a Educação Física voltada para o esporte. A apresentação de um professor-atleta e de exatletas como redentores da imagem esportiva do país de nada contribui com a valorização do profissional de Educação Física no Brasil e, além disso, reforça a perspectiva contida na Lei $n^{\circ} 13.415 / 2017$.

Vemos com preocupação cultural a abordagem jornalística impressa nessa reportagem. Aspectos significativos da Educação Física são negligenciados e, como Betti (2001) defende, é a partir desses exemplos que vemos materializado um problema pedagógico nas relações entre a mídia e a cultura corporal do movimento. $\mathrm{O}$ esporte telespetáculo prevalece, e a concepção hegemônica esportiva conectada às ideias de esforço máximo, vitória, dinheiro e sucesso na vida é a única veiculada nas produções televisivas, não havendo espaço para outras possibilidades, sobremaneira as tantas inerentes à Educação Física na escola.

\section{EUA: profissão atleta}

O terceiro episódio foi exibido em 22 de janeiro de 2017 e tematizado com a relação entre a Educação Física e o esporte espetáculo nos Estados Unidos da América - EUA. Com duração de $11 \mathrm{~min}$. e $18 \mathrm{seg}$., a reportagem inicia com a narrativa do apresentador que já caracteriza os EUA como a maior potência olímpica do mundo.

O discurso construído estabelece forte relação entre o esporte e sua espetacularização midiática, entre o sucesso profissional e o milionário mercado esportivo, que já observamos desde o início: "[...] crianças com alguma habilidade esportiva inevitavelmente sonham com a profissão atleta" (23 seg.). E logo em seguida: "As ligas de esportes profissionais americanos 
arrecadam mais de 32 bilhões de dólares. Mais que 100 bilhões de reais por ano. Produzem imagens encantadoras. Emoções pra todos os gostos. Aos olhos de uma criança americana, praticar esportes é bem mais que uma diversão" (1 min. 11 seg.).

A realidade escolar apresentada é de uma instituição pública com dois professores de Educação Física que apresentam como conteúdos da Educação Física escolar os esportes. As crianças são caracterizadas como engajadas, atléticas e muito proativas quando se trata de praticar esportes. O destaque do sistema de ensino americano são as ligas esportivas que acontecem entre bairros, municípios, estados e em nível nacional. Também a Educação Física é obrigatória no nível básico de ensino e a carga horária semanal é ampliada no ensino médio. Para crianças de 6 a 10 anos (156 min.) e entre 11 e 17 anos (255 min.). Tal contexto contraria a legislação em vigor no Brasil, fruto da Lei nº 13.415/2017, que apresenta a Educação Física, de forma indeterminada, como estudos e práticas.

Dois posicionamentos nos chamam atenção nos discursos dessa reportagem: o voluntariado de treinadores e a invisibilidade da formação profissional para poder trabalhar com Educação Física. A relação desenvolvida com esses discursos sempre traz uma história de sucesso esportivo ou profissional para creditar valor à questão: foi o caso do sucesso de Lebron James e Ron Baker, que tiveram seus pais como técnicos voluntários das equipes de basquetebol por onde passaram durante a educação básica.

Eu sempre senti que poderia jogar basquete universitário e tive a sorte de encontrar técnicos que me colocaram na direção certa. [...] Meu pai era meu professor de Educação Física lá no colégio. Só que ele me tratava como qualquer outro garoto. Isso me fez crescer como pessoa. (6 min. $1 \mathrm{seg}$.).

Não obstante essas críticas, reforçamos a relação desenvolvida entre a Educação Física e os conceitos de cooperação e sociabilidade como fundamento de vida. O depoimento da diretora da Battery Park City School é importante:

Eu me lembro de ter lido um tempo atrás um estudo em que 500 diretores muito bem-sucedidos de grandes empresas americanas foram perguntados sobre qual a maior influência que eles ainda carregavam do período da educação básica. E todos esses executivos disseram: participar de equipes esportivas. Porque eles aprenderam a alcançar os objetivos, a trabalhar de forma colaborativa. Aprenderam que agindo sozinhos talvez fosse impossível ganhar o jogo. (8 min. $43 \mathrm{seg}$.).

Todavia, esta não é a perspectiva dominante da reportagem. A dualidade percebida na narrativa "A Educação Física forma atletas, mas também forma cidadãos dos melhores. Eles devolvem à sociedade o que podem: sorrisos, exemplos" (10 min. 10 seg.) poderia ser a sinopse dessa reportagem, no entanto, a visada que restringe o olhar para um único possível, ser atleta de sucesso, é o que transborda por toda a trajetória enunciativa das imagens e falas, como na finalização da reportagem: "Na terra das esperanças e dos sonhos é de criança que se aprende. Sim. Nós podemos" (10 min. $44 \mathrm{seg}$.). Essa conclusão conecta uma assertiva inicial: a de que o corredor de uma escola é a estrada para a vida adulta.

\section{Japão: consciência de valorização do esporte}

A reportagem que apresenta como a Educação Física é tratada no Japão foi exibida no dia 29 de janeiro de 2017, com 8 min. e 5 seg. de duração, e revela outro olhar possível a partir dos testemunhais. Contudo, a narrativa jornalística continua nas veredas da relação entre esporte e Educação Física para a formação de atletas.

Ainda, a referencialidade de atletas olímpicos de destaque é o discurso dominante na narrativa jornalística, assim como o retorno à apresentação de professores de Educação Física 
voluntários, inclusive professores de outras disciplinas atuando no ensino da Educação Física. "No rigoroso ensino japonês é interessante ver como o esporte se encaixa nos primeiros anos, na maioria das escolas, o mesmo professor que ensina matemática, geografia está à frente também da Educação Física" (1 min. 37 seg.).

O destaque inicial é creditado à diversidade de modalidades esportivas à disposição das crianças. O espaço destinado às práticas esportivas, o rigor no ensino e a valorização do esporte pela escola e pelas crianças são outros pontos reforçados na matéria.

Nessa escola, uniformes de antigos atletas ganham destaque no corredor de entrada. Passado que abre caminho para o futuro quando outra olimpíada se aproxima. Nessa fase de preparativo para os jogos de 2020, Tóquio aproveita pra estimular ainda mais o esporte nas escolas, trazendo convidados especiais. (6 min. 6 seg.).

De forma análoga à dos EUA, "Ao longo do ano existem competições interescolares, regionais e nacionais" (3 min. $40 \mathrm{seg}$.). Em média, são três dias de aula por semana, ou seja, mais de duas horas semanais, sendo complementadas com atividades extracurriculares eleitas pelos próprios alunos, que são desenvolvidas depois das aulas - o bukatsu, que envolve $70 \%$ dos adolescentes. Ponto apresentado em contrariedade às determinações da Lei 13.415/2017, em vigor no Brasil.

Um ponto relevante é a orientação governamental quanto ao currículo, pois no Japão "Existe uma orientação básica do Ministério da Educação sobre as modalidades que devem ser oferecidas no dia a dia da escola, mas cada uma pode adaptar o esporte à sua realidade" (4 min. 59 seg.). Isso é importante porque, como vimos, atividades lúdicas (não esportivizadas), como andar em pernas de pau e em monociclos, são desenvolvidas. Isso auxilia na aprendizagem de novos movimentos, no equilíbrio e no crescimento das crianças. E essa perspectiva é análoga à que vivenciamos hoje com as orientações curriculares nacionais.

Essa última reportagem traz questões interessantes como a de que, para professores, o importante é que as crianças tenham uma experiência útil, aprendendo a trabalhar em conjunto. Não interessa apenas o crescimento físico, mas outros valores como a disciplina e a moral. Também o que de mais positivo observamos nos discursos sobre a relação entre a Educação Física e o esporte no Japão foi o legado construído ao longo dos anos, que apresenta a conscientização de valorização do esporte como seu ponto mais forte.

\section{Considerações finais}

Ao analisar os discursos contidos nas reportagens da Rede Globo de Televisão que enunciaram apresentar a realidade da Educação Física no Brasil e no mundo, concluímos que muito ainda se tem a discutir sobre o papel informativo, ideológico, político e cultural que a mídia televisiva apresenta nestes tempos de incertezas, mudanças densas e retrocessos educacionais anunciados com naturalidade e urgência sob a mácula da retomada do desenvolvimento nacional.

Tais matérias jornalísticas assumem um lugar de fala de autoridade sobre o tema, em que apenas duas escolas públicas são visibilizadas como espelho da Educação Física brasileira de forma generalista e negligenciando os diversos contextos em que se processa o ensino da Educação Física nas diferentes realidades regionais e locais do Brasil.

Como instituto cultural significante quando se trata de oferta de sentidos, os programas televisivos em questão trouxeram à tona possibilidades para se pensar o que a Lei 13.415/2017 propõe, contudo, apresenta sentidos que subjetivamente reforçam suas prerrogativas, como a invisibilidade da formação superior em Educação Física de muitos professores entrevistados, especificamente nos episódios dos EUA, da Inglaterra e do Japão. Também tenta legitimar uma concepção instrumental de educação escolar, neutralizando as 
potencialidades de toda uma construção de Educação Física escolar a partir de uma perspectiva histórica.

Nesse contexto, como discurso social que deve ser tensionado nessas reportagens, trata-se do recorte de conteúdo das aulas de Educação Física destinado exclusivamente aos esportes, sejam individuais ou coletivos, e que não apresentam outras possibilidades curriculares que não sejam estas.

Essa amarra curricular é problemática e nos faz antever futuros jovens que, pela seletividade que o espetáculo esportivo produz, não se transformarão em astros esportivos. Por isso, uma Educação Física mais plural, coletiva, holística e com cada vez menos constituintes competitivos, heroicos e individualistas seria muito mais interessante para um conjunto de reportagens que promete apresentar o que seja a disciplina Educação Física escolar e investigar qual o tamanho da importância da Educação Física na vida de uma pessoa.

\section{Referências}

BAKHTIN, M.; VOLOSHINOV, V. Marxismo e filosofia da linguagem: problemas fundamentais do método sociológico nas ciências da linguagem. 11 ed. São Paulo: Hucitec, 2004.

BETTI, M. Mídias: aliadas ou inimigas da educação física escolar? Motriz. v. 7, n. 2, p. 125129. jul./dez. 2001.

BRASIL. Medida provisória $\mathrm{n}^{\mathrm{o}}$ 746, de 22 de setembro de 2016. Diário Oficial [da] República Federativa do Brasil, Poder Executivo, Brasília, DF, 23 set. 2016. Seção 1, p. 1.

Ministério da Educação. Lei de Diretrizes e Bases da Educação Nacional. LDB 9.394, de 20 de dezembro de 1996.

CHIAPPINI, L. (Org.). Outras linguagens na escola: publicidade, cinema e TV, rádio, jogos, informática. 4 ed. São Paulo: Cortez, 2004. (Coleção Aprendendo a ensinar com textos, v. 6).

FAIRCLOUGH, N. Discurso e mudança social. Brasília: Editora UnB, 2001.

FISCHER, R. M. B. Televisão e educação: fluir e pensar a TV. 3. ed. Belo Horizonte: Autêntica, 2006.

FOUCAULT, M. A arqueologia do saber. 4. ed. Rio de Janeiro: Forense Universitária, 1995.

MAGALHÃES, F. L. J. Veja, isto é, leia. A imagem e a imagem nos discursos de capas das revistas Veja e Isto é: produção e disputas de sentido na mídia. Teresina: EDUFPI, 2003. 158 p.

VERÓN, E. Fragmentos de um tecido. São Leopoldo, RS: Editora Unisinos, 2004. 
Endereço para correspondência:

fabio.costa.002@acad.pucrs.br

Fábio Soares da Costa

Pontifícia Universidade Católica do Rio Grande do Sul

Faculdade de Educação PUCRS.

Av Ipiranga $n^{\circ} 6681$

Partenon

90169900 - Porto Alegre, RS - Brasil 